Research Article

\title{
The Relationship among the Ecological Factors and Population of Bactrocera dorsalis in Mango Orchards of District Mirpur Khas, Sindh, Pakistan
}

\author{
Aiman Amur ${ }^{1 *}$, Nasreen Memon ${ }^{1},{\text { Pervaiz } \text { Khan }^{2} \text { and Fozia Gull }}^{3}$
}

${ }^{1}$ Department of Zoology, University of Sindh, Jamshoro, Pakistan; ${ }^{2}$ Institute of Marine Reference Collection and Resources Centre, University of Karachi, Pakistan; ${ }^{3}$ Departmentof Biochemistry, Shah Abdul Latife University, Khairpur, Sindh, Pakistan.

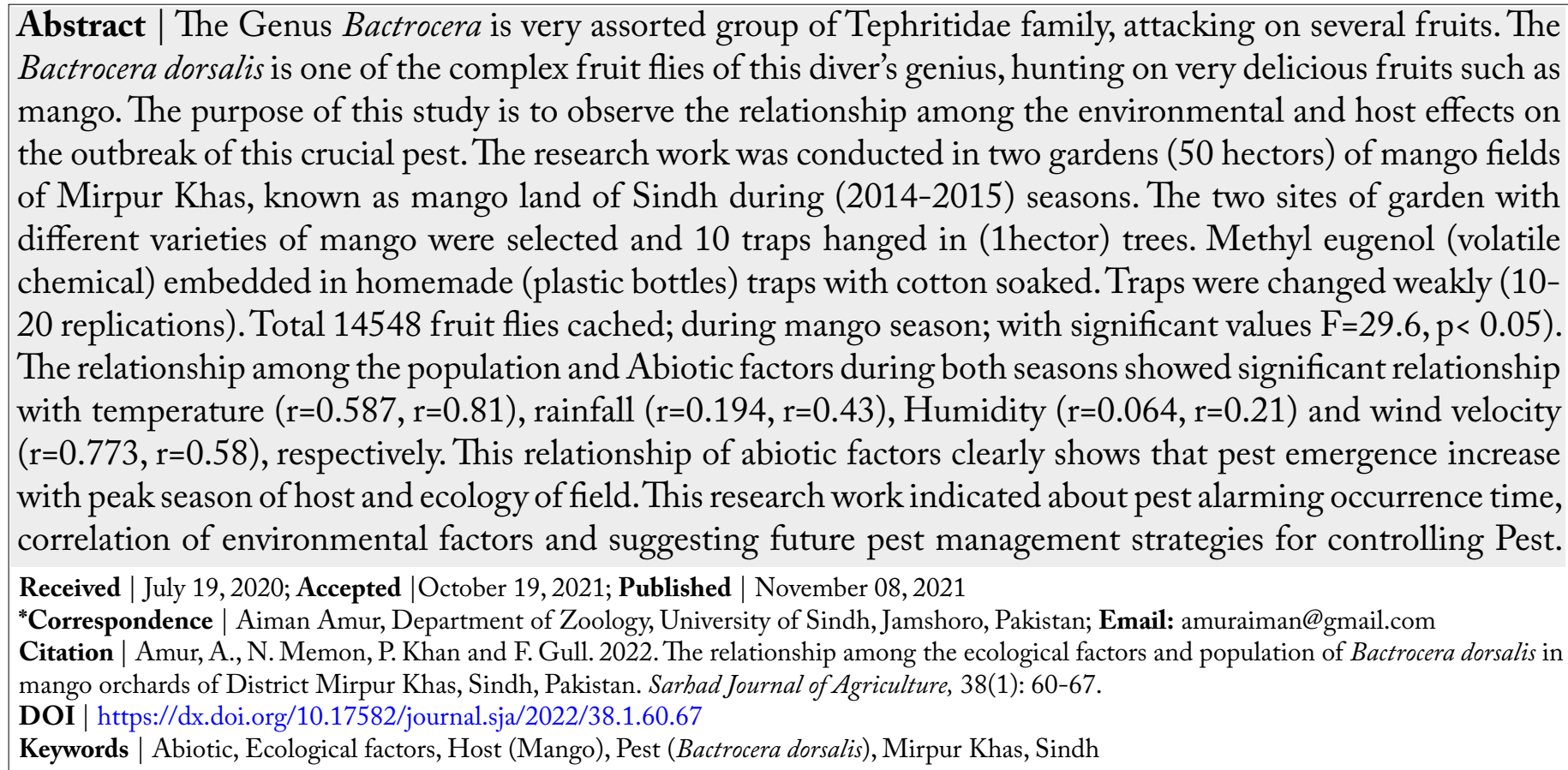

\section{Introduction}

$\mathrm{M}$ ango (Mangifera indica L.) is very delicious fruit of Pakistan; which is disruptive by most common pest fruit flies. Although all over world is under the threats of these pest for all fruit crops. Seventy kinds of fruit fly species attacked on different fruit crops (Garcia, 2009).

\section{Genus Bactrocera}

The genus Bactrocera is the most divers genus of family Tephritidae attacking on fruits, most important species are these Bactrocera dorsalis (Oriental fruit fly),
Bactrocera curcubitae (Melon fly), Bactrocera olea e (O1ive fruit fly), Bactrocera tryoni (Queensland fruit fly), and Bactrocera zonata (Peach fruit fly) (Garcia, 2009), all these species immensely hostile particularly oriental fruit fly is intimidations for mango fruits ( $\mathrm{Ma}-$ lavasi et al., 2000). Mostly, the abundance and host places of fruit fly pest influenced by biotic and abiotic attacks. The occurrences of infestation of fruit fly is changed because of environmental attacks (Kannan and Rao, 2006).

The monitoring of pests are extensive theoretically harmful influence on ecologically and socioeconomMarch 2022 | Volume 38 | Issue 1 | Page 60 
ically (Lewis et al., 1997; Aluja and Mangan, 2008; Thomas, 1999), The environmental management strategies are more successful, through these schemes there is less ecological distresses and more protective supervision against improbabilities (Verkerk et al., 1998; Lindquist, 2000). The unsuccessful pest control management have absence of understandings about the life cycle of pest, long lasting population dynamics relationship to ecosystem (i.e., agro ecosystem) and world weather procedures (Stenseth et al., 2002).

\section{The Ecological Factors}

According to ecological studies two factors like biotic and abiotic factors influence the mortality and regulation of population to Tephritidae, such as being a biotic factor parasitoid wasps are play significant role in death issues; destructive ants and pathogens causative to Tephritidae inhabitant's regulation.

The abiotic factors like temperature and rainfall play most important role for occurrence of fruit flies (Ovruski et al., 2000; Aluja et al., 2005; Celedonio-Hurtado et al., 1995). The emergence of oriental fruit fly gradually increase in the beginning of March, as the host fruit (late mangoes grown starts); at the end of May the pest population intensification increase because during this time mango fruit becomes mature and it is capable for the course of harvesting. Fruit flies pest infestation wide-ranging with weather parameters (Kannan and Rao, 2006). The abiotic factors (temperature, rainfall, humidity and wind velocity) directly influences on the growth and demography of pests; and circuitously disturb biotic availabilities such as host and regular opponents (Verghese et al., 2002). Many regions of the world, where the different pest creatures like fruit flies by islands/mainland areas find their ways by storms or tornedo and high wind velocity recommended and transported infested of fruits and vegetables; frequently movement and presenting common abundance of fruit flies (pest) (Kaiser and Cummings, 1958).

This study proposed the ecological defense in the pest control strategies, survey the relationship supervision among live and non-live things for the eradicate pest infest from fruits, broad thinking of this ecological investigation is to offer strategy makers, Platform troughs and researchers with new facts of host and pest relationship with the alternative climatic conditions.

\section{Materials and Methods}

\section{Study site}

This research work was carried out during the mango season of 2014-2015 (June-September upto $1^{\text {st }}$ week of October). The orchards of Mirpur Khas, Sindh has a [Longitude $69^{\circ} 00^{\prime} 50.6^{\prime \prime} \mathrm{E}$ and Latitude $\left.25^{\circ} 31^{\prime} 39.3^{\prime \prime} \mathrm{N}\right]$. Out of 50 hectors; selected the 2 hectors divided in 2 blocks with distanced on opposite sides. Around ten varieties are available in fifty hectors and density of trees per hector 200 trees (distance between each tree $30 \mathrm{ft}$.), approximately age of tree 30-35 years, their canopy diameter more than $10 \mathrm{~m}$ with height 15-18 $\mathrm{m}$ large.

\section{Quantity of adult fly population variations}

The study site (2 blocks of mango orchard) placed with ten traps, The traps were homemade 2-3 litters plastic bottles embedded with water soaked cotton swab dip with attractant volatile chemical of fruit fly (methyl eugenole) was kept in bottom of the bottle. All these traps were slung in the selected mango orchards. The traps were placed equally; no corner of each selected block was left uncovered. Each trap was suspended branch of tree about $2-3 \mathrm{~m}$ above the field. There were 10-12 replication of each trap was got from each block during whole mango season. The traps were checked after every 7 days during whole study period. All specimens were shifted in Jar, dip with $70 \%$ alcohol and kept in laboratory for counting.

Weakly traps calculation were changed to FTD values (flies per trap per day) by using formula: Total Number of flies / Number of traps $x$ days of experience (Agency., 2003). By this technique difference between each trap counting or capture time was identical.

\section{Weather analysis}

The effect of weather parameters on abundance of fruit flies pest were carried out by associating with climatic observation (metrological) and fruit flies population. This study was based on four variables of weather parameters temperature $\left({ }^{\circ} \mathrm{C}\right)$, rainfall $(\mathrm{mm})$, Humidity (\%) and wind ( $\mathrm{km} / \mathrm{hr}$.) (www.timanddate. com 2014 and 2015). During the experimental observation it was noted that all the above weather parameters significantly effect on the pest population in Mirpur Khas location.

\section{Statistics analysis}

Occurrence of fruit fly (flies per trap per day) FTD 


\section{Fortnightly population data per- month}

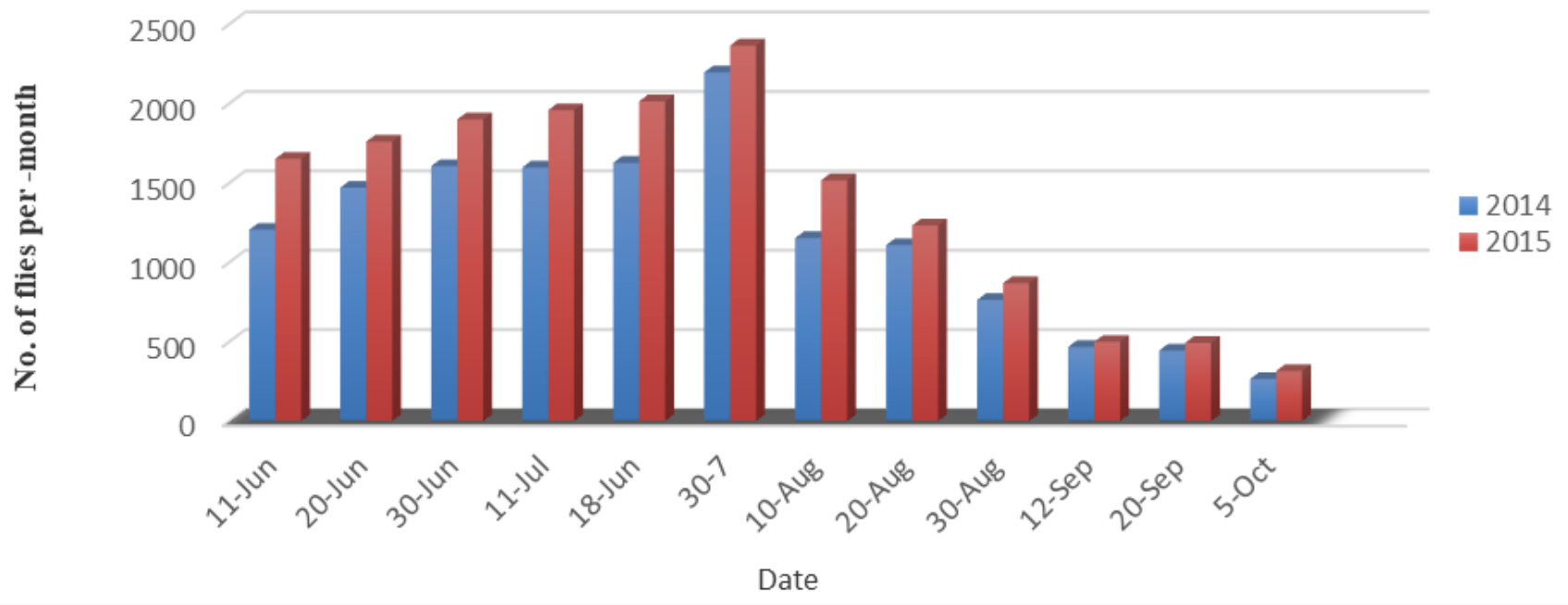

Figure 1: shows the (month wise) yearly population of fruit flies during 2014-2015.

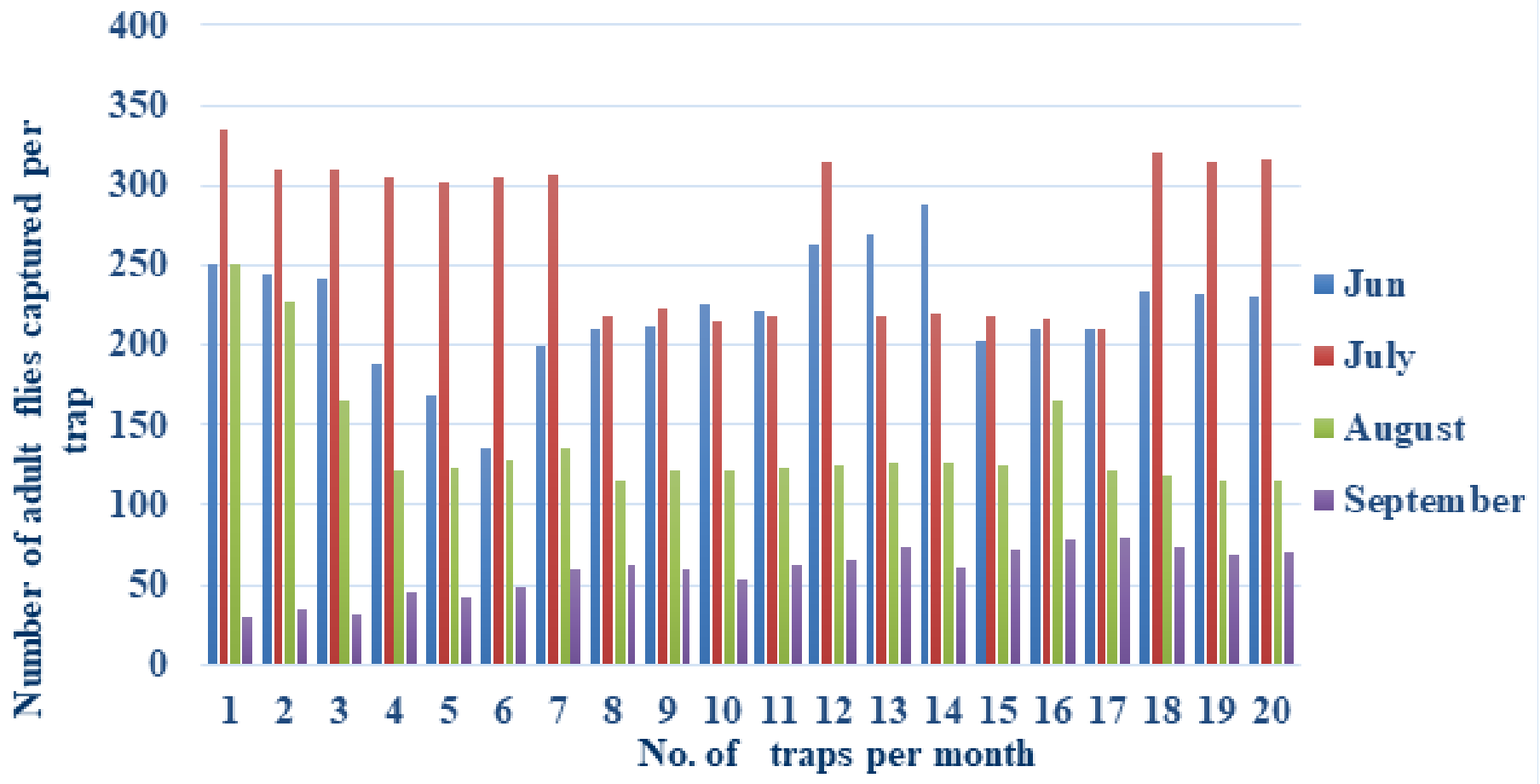

Figure 2: Shows the per trap population during 2014.

values of $B$. dorsalis. The statically examination were followed the experiments of (Gomez and Gomez, 1984) used for observed LSD (least significant difference) STATISTICA 7.0 and found the statically designing correlation among the pest population and metrological parameter by SPSS 21.0.

\section{Results and Discussion}

During the present study, it was observed that oriental fruit fly is very dangerous pest in Mirpur Khas Sindh, these orchards of mango land of Sindh is endangered to concentrated controlling, manual trap sprays for fruit flies was applied during peak mango season from June to September ( ${ }^{1 s t}$ weak of October2014-2015) in Mirpur Khas with significant values $F=29.6, p<0.05$. The calculated number of flies were cached during July (12077) it was maximum number and while in September (2471) calculated the minimum number of flies (during both years' successive seasons). Figure 1 total numbers of adults 14548 were cached 2.35\% only other species of Bactrocera species were cached in lures (Figure 2 and 3). According to per trap study of $B$. dorsalis during the peak host in June and July with two years successive seasons, the pest population was highest number during the July (flies; 5394 and 6683; 


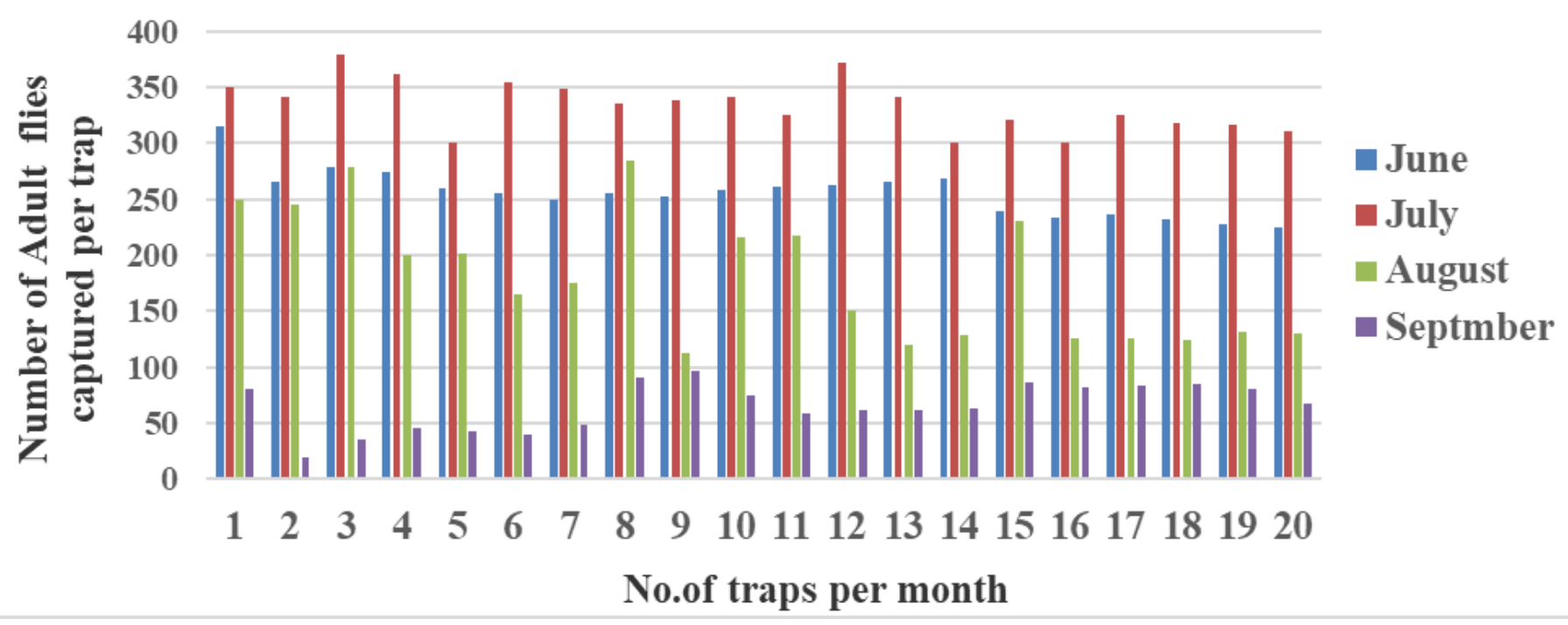

Figure 3: Shows the per trap population during 2015.
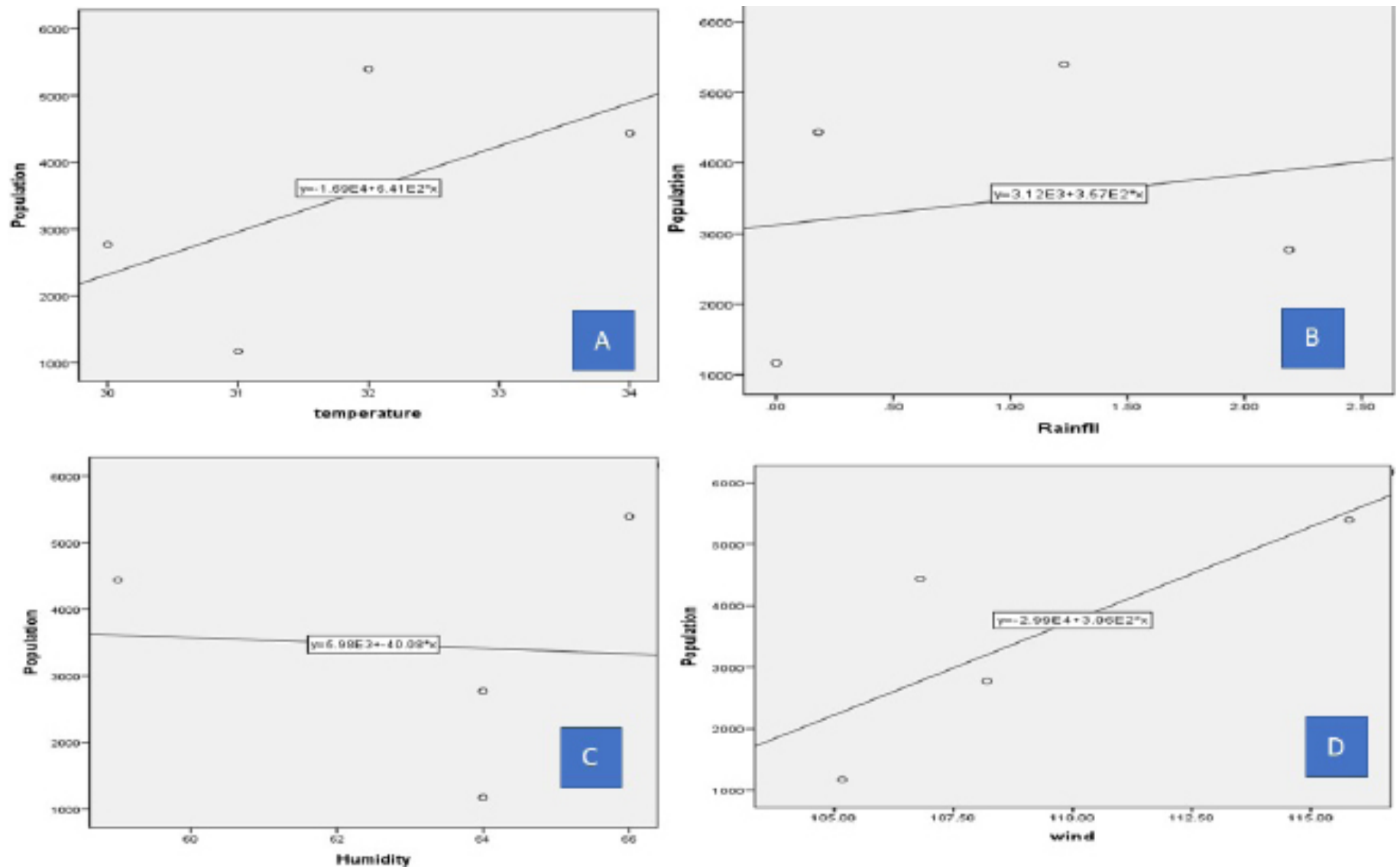

Figure 4: $(a, b, c, d)$ shows the + corelation b/wAv. Temp.; weak (+ve) correlation b/w Av. Rainfall; weak (-ve) correlation b/w Av. Humidity, strong (+ve) correlation between average wind with Outbreak of Bactrocera dorsalis in Mirpur khas locality of Sindh during 2014.

2014 and 2015 fruit flies per trap respectively) and minimum number of pest (fruit flies) was recorded during September (with $1^{\text {st }}$ week of October) (Less No. of flies: 1170 and 1301; 2014 and 2015 respectively). Above results clearly shows that abundance of fruit fly Bactrocera dorsalis pest overlapped with maturing stage of mango season. The pest fruit fly gradually increase in Mirpur Khas locality of Sindh in the last week of May, and Mango is started fully ripened up to June it would starved. The proper regular increase in population occurrence noticeably was recorded from starting of June afterward it peak occurrence noted in July.

Relationship studies among fruit fly and environmental factors in figures. According to study of 2014 Figure 4 (a, b, c, d), (Figure 4a) showed the moderate positive correlation among temperature $(\mathrm{r}=0.587)$ 
and population of oriental fruit fly; (Figure 4b) showed the weak positive correlation among rain fall ( $r=0.194)$, (Figure 4c) Showed the weak negative correlation among the humidity $(\mathrm{r}=-0.064)$, (Figure $4 \mathrm{~d}$ ) Showed strong positive correlation between wind velocity ( $\mathrm{r}=0.773$ ) with Bactrocera dorsalis.

According to results of (Pearson's correlation) among pest and weather parameters in 2015; Figure 5 (a, b, c, d), (Figure 5a), showed the fruit fly population strongly positive correlation with temperature $(\mathrm{r}=0.81)$, population of fruit fly, (Figure 5b) showed (moderate) co-relation with rainfall $(\mathrm{r}=0.43$ ), (Figure $5 \mathrm{c}$ ) the humidity $(r=0.21)$ showed the weak positive co-relation with population, (Figure $5 \mathrm{~d}$ ) the population showed the moderate positive co-relation with the wind velocity $(\mathrm{r}=0.58)$. Along the current situation this study is based on cyclical differences of two years.

The Mirpur Khas is locality of various fruit crops, which are providing the chance of outbreak of fruit fly population. The peak outbreak of $B$. dorsalis in Sindh are June and July, because during this month the host fruit of pest mango is fully ripened and grad-
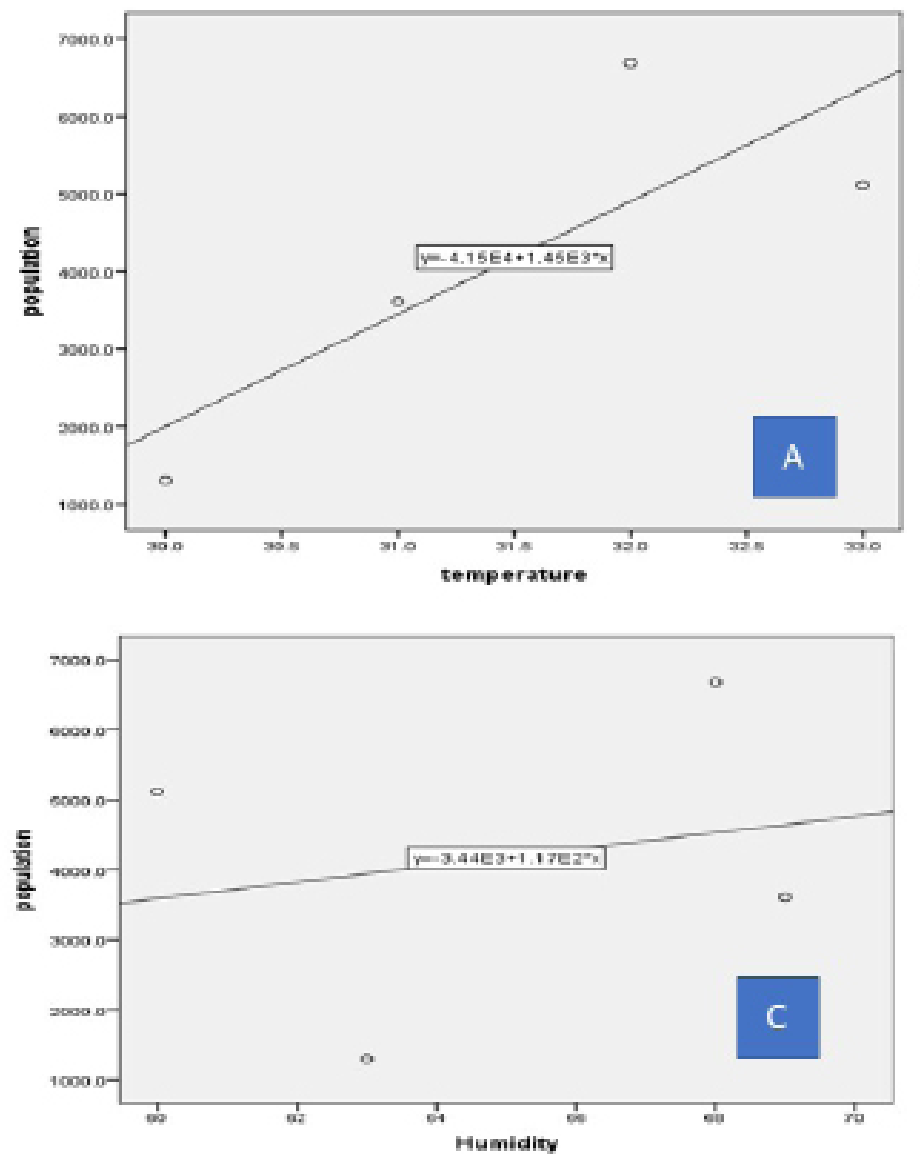

ually declined population of oriental fruit fly in the mid of August, The cause of decline population in august because the host fruit almost harvest during last week of this month. When compare the results of two years study it was found that pest population during 2014 is less in numbers as compare to 2015, reason is that the rain was scarcely fall during 2014, for that the population shows weak co-relation with rain and negative (-) co relation with humidity, humidity being occurs with raining there for humidity occurs for short time in 2014. The number of fruit flies increased during 2015 because sufficient rain fall, which occurs moderate positive $(+)$ correlation with pest while same as in 2015 the humidity also in positive influence on fruit fly. The continuously effects of pest control strategies mostly elucidated by a limited thought full of the issues that will determined the durable population dynamics of a particular irritants or pest multifaceted (Aluja and Mangan, 2008), climatic conditions such as (temperature, rain fall and relative humidity) have obvious effect on Bactrocera species (Tephritidae family) growth and survival (Mwatawala et al., 2006). (Danjuma et al., 2013) Stated that
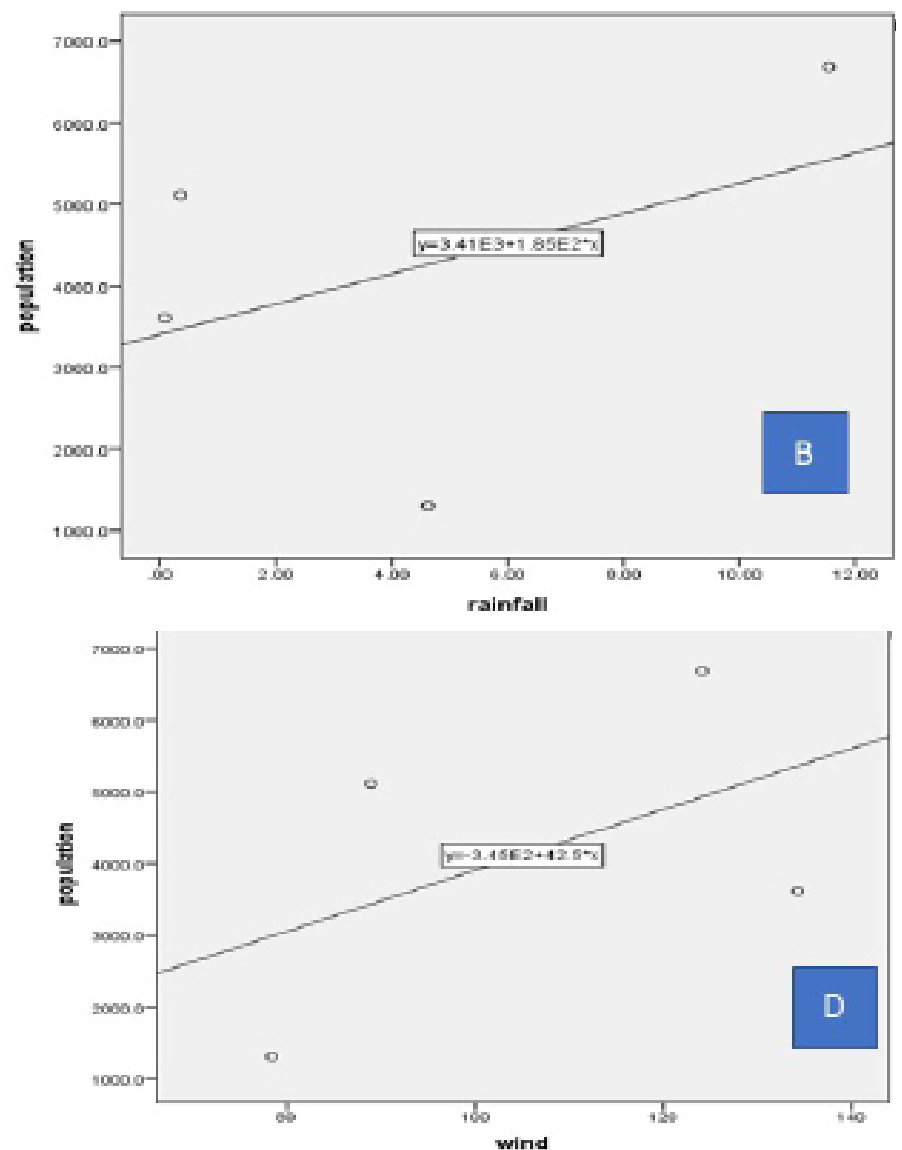

Figure 5: $(a, b, c, d)$ shows the strong (+ve)corelation b/w Av.Temp.; Moderate (+ve) correlation b/w Av. Rainfall; weak (-ve) correlation b/w Av. Humidity, Moderate (+ve) correlation between average wind with outbreak of Bactrocera dorsalis in Mirpur khas locality of Sindh during 2015. 
temperature parameter of weather influence with least growth thresholds for Bactrocera dorsalis species in Thailand country. Present study contradict with study of (Danjuma et al., 2013) because due to local weather effect, the Mirpur khas district is temperate region so here the moderate temperature have the maximum influence on population of pest as well as host as shown in Figures (4a and 5a), According (Aluja et al., 2012) the population developmental growth is maximum when the rain all occur, the temperature and rainfall direct effect on population of Anastrepha obliqua. Same results were found in these studies, the both environmental factors effect on population of Bactrocera dorsalis (Figure 4a, 4b, 5a and 5b). The population of fruit flies also influenced by the seasonal variation in rainfall and most important weather irregularities (Montecinos and Aceituno, 2003), the host (fruit) production will favor in out breaks of pest population, the monthly rate of pest population gradually increase with host maturity season, same research work was discussed by the (Lundberg et al., 2000) that population managing and monitoring is depending on increasing the host variety and taxa. According to the study (Lindquist, 2000; Klassen, 2005) protest that effect of mutually native and worldwide difference on fruit fly pest inhabitants and the idea about management of these kind of pests positively measured over significant, by all cultivators integrate in their given area wide or particular regions (Klassen, 2005; Lindquist, 2000). The occurrence of Tephritidae species has intensely endangered the different fruit crops. The mango is main host of oriental fruit fly as compare to other host. The oriental fruit fly $(B$. dorsalis) is eighty five percent threatened the mango orchards in Sindh Pakistan, other fruit flies like B.zonata, B.correcta slightly hosting on this cash fruit (mango) as for; there is availability of their major host during mango season. Same thoughts was also given by (Kafi, 1986). (Mahmood and Mishkatullah, 2007) described that Bactrocera species outbreak increase with the availability of host. The theme of this research work is relate with above scientist; likewise the richness of fruit flies (oriental fruit fly) was found during the peak of host season (June and July) as shown in Figure 1,2 and 3.

\section{Conclusions and Recommendations}

It was concluded that fly population begin to increase from end of May Therefore, farmers and gardeners should apply control measures according to fruit fly population; during the fruit start ripened and secondly farmers and gardeners should be very careful for Abiotic factors, such as rainy season. As fly population is never reach economic injury level. In order to reduce their population drastically before and even during fruiting months of plants (biotic factors). Cultural operation should be carried out on the farm e.g. picking of fallen fruits and burying them accordingly. Fruit can also be bagged to prevent ovi position of female fly on them.

These results surely indicate that the environmental factors like Abiotic and biotic factors, like presence of host and climatic conditions directly co-relate with pest populations. Genders prejudgment in guardianship and average of rainy season is directly correlated with population dynamics of Bactrocera dorsalis species in mango orchards during both years. According to annual order the climatic factors changes the values of pest population density directly or indirectly. The local climatic changes influence population dynamics of the pest. The temperature, air and rainfall direct affect the pest and host population both the study has provided a good background and basic information which is handy for pest control agencies, pest managers as well as governmental and non-governmental organizations saddled with pest's management.

\section{Acknowledgements}

I am highly gratefully to District Officer, Mirpur Khas (Divisional Headquarters of Mirpur Khas Sindh, $\mathrm{Pa}-$ kistan) for their helped and permission doing my research in different orchards in the study area. I am also thankful to growers of fruity land of this locality.

\section{Novelty Statement}

This is a novel approach to observe population occurrence of Bactrocera dorsalis with influence of the Ecological factors on Mango Land of Sindh (Mirpur Khas). Therefore, the study has significant influence of ecological factors on population of pest and host occurrence.

\section{Author's Contribution}

Aiman Amur: Conducted the research. Nasreen Memon: Helped in article writing. Pervaiz Khan: Helped in literature review Fozia Gull: Proofreading and format setting. 
Conflict of interest

The authors have declared no conflict of interest.

\section{References}

Agency, I.A.E. 2003. Trapping Guidelines For Area-Wide Fruit Fly Programmes.

Aluja, M. and Mangan, R. L. 2008. Fruit Fly (Diptera: Tephritidae) Host Status Determination: Critical Conceptual, Methodological, And Regulatory Considerations. Annu. Rev. Entomol., 53: 473-502. https://doi.org/10.1146/annurev.ento.53.103106.093350

Aluja, M., Ordano, M., Guillén, L. and Rull,J. 2012. Understanding Long-Term Fruit Fly (Diptera: Tephritidae) Population Dynamics: Implications For Areawide Management. J. Econ. Entomol., 105: 823-836. https://doi.org/10.1603/ EC11353

Aluja, M., Sivinski, J., Rull, J. and Hodgson, P.J. 2005. Behavior And predation of fruit fly larvae (Anastrepha Spp.) (Diptera: Tephritidae) after exiting fruit in four types of habitats in tropical Veracruz, Mexico. Enviro. Entomol., 34: 1507-1516. https://doi.org/10.1603/0046225X-34.6.1507

Celedonio-Hurtado, H., Aluja, M. and Liedo, P. 1995. Adult population fluctuations of anastrepha species (Diptera: Tephritidae) In tropical orchard habitats of chiapas, Mexico. Environ. Entomol., 24: 861-869. https://doi. org/10.1093/ee/24.4.861

Celedonio-Hurtado, H., Liedo, P., Aluja, M., Guillen, J., Berrigan, D. and Carey, J. 1988. demography of anastrepha ludens, A. Obliqua and A. Serpentina (Diptera: Tephritidae) In Mexico. Florida Entomol., 111-120. https://doi. org/10.2307/3495357

Danjuma, S., Boonrotpong, S., Thaochan, N., Permkam, S. and Satasook, C. 2013. Biodiversity of the genus bactrocera (Diptera: Tephritidae) In guava Psidium guajava L. orchards in different agro-forested locations of Southern Thailand. Int. J. Chem. Environ. Biol. Sci., 1: 538-554.

Garcia, F.R.M. 2009. Fruit Fly: Biological and ecological aspects. Current trends in fruit flies control on perennial crops and research prospects. Kerala: Transworld Res. Network., 1-35.

Gomez, K.A. and Gomez, A.A. 1984. Statistical procedures for agricultural research, John Wiley \& Sons.
Kafi, A. 1986. Progress and problems in controlling fruit flies infestation. Fao, Rapa, Bangkock. 1619.

Kaiser, I.H. and Cummings, J.N. 1958. Ph, carbon dioxide, oxygen, hemoglobin and plasma electrolytes in blood of pregnant goats and their fetuses. Am. J. Physiol. Legacy Content, 195: 481-486. https://doi.org/10.1152/ajplegacy.1958.195.2.481

Kannan, M. and Rao, N.V.2006. Ecological studies on mango fruit fly, bactrocera dorsalis hendel. Annal. Plant Prot. Sci., 14: 340-342.

Klassen, W. 2005. Area-Wide integrated pest management and the sterile insect technique. Sterile Insect TTechnique. Springer.

Lewis, W.J., Van Lenteren, J., Phatak, S.C. and Tumlinson, J. 1997. A total system approach to sustainable pest management. Proceed. $\mathrm{Na}-$ tional Acad Sci., 94: 12243-12248. https://doi. org/10.1073/pnas.94.23.12243

Lindquist, D. 2000. Area-wide control of fruit flies and other insect pests. Joint proceedings of the international conference on Area-Wide Control of Insect Pests, 28 May-2 June, 1998 and The fifth international symposium on "Fruit Flies of Economic Importance”, Penang, Malaysia, June 1-5, 1998. Penang, Malaysia.

Lundberg, P., Ranta, E., Ripa, J. and Kaitala, V. 2000. Population variability in space and time. Trends Ecol. Evol., 15: 460-464. https://doi. org/10.1016/S0169-5347(00)01981-9

Mahmood, K. and Mishkatullah. 2007. Population Dynamics of three species of genus bactrocera (Diptera: Tephritidae: Dacinae) in Bari, Chakwal (Punjab). Pak J. Zool., 39: 123-126.

Malavasi, A., Zucchi, R.A. and Sugayama, R. 2000. Fruit flies of economic importance in Brazil: basic and applied knowledge. Holos Editora Ribeirão Preto.

Montecinos, A. and Aceituno, P. 2003. Seasonality of the ENSO-related rainfall variability in central chile and associated circulation anomalies. J. Clim., 16: 281-296. https://doi.org/10.1175/15 20-0442(2003)016<0281:SOTERR >2.0.CO;2

Mwatawala, M., De Meyer, M., Makundi, R. and Maerere, A. 2006. Seasonality and host utilization of the invasive fruit fly, bactrocera invadens (Dipt., Tephritidae) in central Tanzania. J. Appl. Entomol., 130: 530-537. https://doi. org/10.1111/j.1439-0418.2006.01099.x

Ovruski, S., Aluja, M., Sivinski, J. and Wharton, R. 
2000. Hymenopteran parasitoids on fruit-infesting tephritidae (Diptera) in Latin America and the southern United States: diversity, distribution, taxonomic status and their use in fruit fly biological control. Integr. Pest Mgt Rev., 5: 81-107. https://doi. org/10.1023/A:1009652431251

Stenseth, N.C., Mysterud, A., Ottersen, G., Hurrell, J.W., Chan, K.S. and Lima, M. 2002. Ecological effects of climate fluctuations. Science, 297: 1292-1296. https://doi.org/10.1126/science. 1071281

Thomas, M.B. 1999. Ecological approaches and the development of "truly integrated" pest management. Proc. National Acad. Sci., 96: 5944-5951. https://doi.org/10.1073/pnas.96.11.5944

Verghese, A., Madhura, H., Kamala Jayanthi, P. and Stonehouse, J.M. 2002. Fruit flies of economic significance in India, with special reference to bactrocera dorsalis (Hendel). Proceedings of $6^{\text {th }}$ Int. Fruit Fly Symp., 6-10.

Verkerk, R., Leather, S. and Wright, D. 1998. The potential for manipulating crop-pest-natural enemy interactions for improved insect pest management. Bull. Entomol. Res., 88: 493-501. https://doi.org/10.1017/S0007485300026018 